\title{
Exploring the Relationship between Omega-3 Index Levels and Cancer-Related Cognitive Impairment among Women with Breast Cancer
}

\author{
Arash Asher MD¹, Jamie Myers², PhD RN, AOCNS, Rachel Baynes MA¹, Galen Cook-Wiens, MS ${ }^{1}$,William Harris, PhD³ \\ ${ }^{1}$ Samuel Oschin Comprehensive Cancer Institute at Cedars-Sinai Medical Center \\ ${ }^{2}$ School of Nursing at University of Kansas \\ ${ }^{3}$ Sanford School of Medicine at University of South Dakota
}

\section{BACKGROUND \\ - Cancer-related perceived cognitive} impairment $(\mathbf{P C l})$ is a common survivorship problem affecting at least $35 \%$ of breast cancer survivors.

- $\mathrm{PCl}$ can be extremely distressing and may profoundly impact quality of life, feasibility of returning to work, and social reintegration.

- Symptoms can include difficulty with shortterm memory, attention or concentration, processing speed, and executive function

- No readily available biomarkers that can identify survivors at higher risk for these symptoms.

- Decreased omega-3 fatty acid levels have been associated with increased levels of inflammatory markers and diminished cognitive function and brain volume in other populations.

- No study to date has evaluated the relationship between Omega-3 levels with $\mathrm{PCl}$ in the cancer survivorship setting.

\section{METHODS}

- We collected finger-spot blood samples from 39 participants who were part of our cognitive rehabilitation program for $\mathrm{PCl}$.

- These samples were analyzed for Omega-3 fatty acid index [expressed as a percent of total erythrocyte fatty acids including EPA and $\mathrm{DHA}$.

- PROMIS Applied Cognition - General concerns (Gen Concerns) and Cognitive Abilities (Cog Ability) Short Forms were completed prior to the rehabilitation intervention.

- Both instruments include 8 items and have been validated for use in cancer patients.

- PROMIS GEN Concerns assesses troubling cognitive changes such as thought formation and attention. (Higher scores indicate worse cognitive function).

- PROMIS Cog Ability assesses concentration and memory. (Higher scores indicate better cognitive function).

\begin{tabular}{|c|c|c|c|c|}
\hline \multicolumn{5}{|c|}{ Patient Demographics $(n=39)$} \\
\hline Age & \multicolumn{2}{|c|}{ Stage of Breast Cancer } & \multicolumn{2}{|l|}{ Omega Characteristics } \\
\hline \multirow[t]{4}{*}{ Mean: $51.6( \pm 12.13)$} & I & $16(42.1 \%)$ & Current DHA/EPA Use & $12(30.8 \%)$ \\
\hline & II & 18 (47.4\%) & Omega 3 Index & Mean: $5.24 \pm 1.60$ \\
\hline & III & $3(7.9 \%)$ & & \\
\hline & Unknown & $2(5.2 \%)$ & & \\
\hline
\end{tabular}

\section{RESULTS}

Modest but statistically significant correlation between low Omega-3 fatty acid indices and participants' report of worse cognitive function on both the PROMIS Gen Concerns and PROMIS Cog Abilities

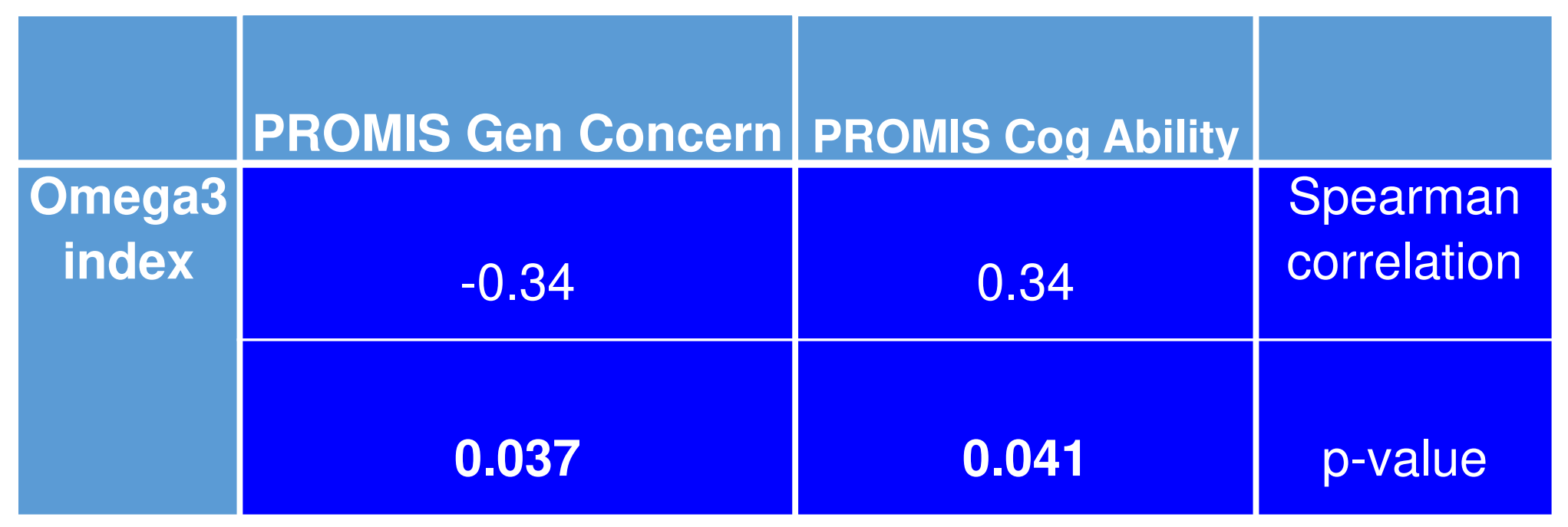

\section{CONCLUSIONS}

- If the above correlation is validated with a larger sample, this simple test may be able to be used as an inexpensive biomarker for $\mathrm{PCl}$.

- Increased intake of foods rich in Omega 3 is postulated to benefit cognitive function in other populations but has yet to be examined for the management of $\mathrm{PCl}$ in the cancer survivorship setting.

- Optimization of the Omega 3 index could represent a safe, low-cost intervention that can be disseminated broadly.

\section{References}

1. Farzaneh-Far R, Harris WS, Garg S, Na B, Whooley MA (2009) Inverse association of erythrocyte n-3 fatty acid levels with inflammatory biomarkers in patients with stable coronary artery disease: The Heart and Soul Study. Atherosclerosis 205 (2):538-543. doi:10.1016/j.atherosclerosis.2008.12.013

2. Fontes JD, Rahman F, Lacey S, Larson MG, Vasan RS, Benjamin EJ, Harris WS, Robins SJ (2015) Red blood cell fatty acids and biomarkers of inflammation: A cross-sectional study in a community-based cohort. Atherosclerosis 240:431-466

3. Grenon SM, Conte MS, Nosova E, Alley H, Chong K, Harris WS, Vittinghoff E, Owens CD (2013) Association between n-3 polyunsaturated fatty acid content of red blood cells and inflammatory biomarkers in patients with peripheral artery disease. J Vasc Surg 58 (5):1283-1290. doi:10.1016/j.jvs.2013.05.024

4. Johnston DT, Deuster PA, Harris WS, Macrae H, Dretsch MN (2013) Red blood cell omega-3 fatty acid levels and neurocognitive performance in deployed U.S. Servicemembers. Nutritional Neuroscience $2013(16): 30-38$

5. Pottala JV, Yaffe K, Robinson JG, Espeland MA, Wallace R, Harris WS (2014) Higher RBC EPA + DHA

corresponds with larger total brain and hippocampal volumes: WHIMS-MRI study. Neurology 82 (5):435-442 doi:10.1212/wnl.0000000000000080

6. Tan ZS, Harris WS, Beiser AS, Au R, Himali JJ, Debette S, Pikula A, DeCarli C, Wolf PA, Vasan RS, Robins SJ, Seshadri S (2012) Red blood cell omega-3 fatty acid levels and markers of accelerated brain aging. Neurobiology 78:658-664 